\title{
Evaluation of RapidEye-3 Satellite Data for Assessing Water Turbidity of Lake Borabey ${ }^{\dagger}$
}

\author{
Gordana Kaplan 1,*, Zehra Yigit Avdan ${ }^{2}$, Serdar Goncu ${ }^{2}$ and Ugur Avdan 1 \\ 1 Earth and Space Institute, Eskisehir Technical University, 26555 Eskisehir, Turkey; \\ uavdan@eskisehir.edu.tr \\ 2 Department of Environmental Engineering, Eskisehir Technical University, 26555 Eskisehir, Turkey; \\ zyigit@eskisehir.edu.tr (Z.Y.A.); sgoncu@eskisehir.edu.tr (S.G.) \\ * Correspondence: kaplangorde@gmail.com; Tel.: +90-536-697-5605 \\ + Presented at the 4th International Electronic Conference on Water Sciences, 13-29 November 2019; \\ Available online: https://ecws-4.sciforum.net/.
}

Published: 12 November 2019

\begin{abstract}
In water resources management, remote sensing data and techniques are essential in watershed characterization and monitoring, especially when no data are available. Water quality is usually assessed through in-situ measurements that require high cost and time. Water quality parameters help in decision making regarding the further use of water-based on its quality. Turbidity is an important water quality parameter and an indicator of water pollution. In the past few decades, remote sensing has been widely used in water quality research. In this study, we compare turbidity parameters retrieved from a high-resolution image with in-situ measurements collected from Borabey Lake, Turkey. Here, the use of RapidEye-3 images (5 m-resolution) allows for detailed assessment of spatio-temporal evaluation of turbidity, through the normalized difference turbidity index (NDTI). The turbidity results were then compared with data from 21 insitu measurements collected in the same period. The actual water turbidity measurements showed high correlation with the estimated NDTI mean values with an $\mathrm{R}^{2}$ of 0.84 . The research findings support the use of remote sensing data of RadipEye-3 to estimate water quality parameters in small water areas. For future studies, we recommend investigating different water quality parameters using high-resolution remote sensing data.
\end{abstract}

Keywords: remote sensing; water quality; water turbidity; turbidity index

(C) 2019 by the authors; licensee MDPI, Basel, Switzerland. This article is an open access article distributed under the terms and conditions of the Creative Commons by Attribution (CC-BY) license (http://creativecommons.org/licenses/by/4.0/). 